\title{
Evaluation of Ginger (Zingiber officinale) Genotypes for High Yield and Resistance to Soft Rot Suitable for Gudalur Regions in Nilgiris District
}

\author{
S. Karthikeyan ${ }^{1}$, M. Anand ${ }^{1}$, S. Malathi ${ }^{1}$ and S. Manonmani ${ }^{2}$ \\ ${ }^{1}$ Horticultural Research Station, Tamil Nadu Agricultural University, \\ Ooty, The Nilgiris, India \\ ${ }^{2}$ Department of Oilseeds, TNAU, Coimbatore, India \\ *Corresponding author
}

\section{A B S T R A C T}

Keywords

Evaluation, Ginger, Gudalur, Genotypes,

High yield, Soft rot resistance

Article Info

Accepted:

20 June 2018

Available Online:

10 July 2018
The experiment was conducted to assess the performance of ginger genotypes suitable for high yield and resistance to soft rot disease in Gudalur block of The Nilgiris district. Fourteen genotypes were collected and the performance was studied for three seasons during the year 2015 2018. Acc-578 showed better performance in terms of vegetative and yield characters followed by Mahima. IISR-1 GB, Maran and Thadimaran recorded moderate resistance to per cent disease incidence under field conditions in the Nilgiris.

\section{Introduction}

Ginger (Zingiber officinale Rosc.) is a herbaceous perennial, belonging to the family Zingiberaceae, valued for its aroma, flavour and medicinal properties. It is a major spice crop of which the rhizomes are used as spice. India is one of the leading producers of ginger in the world accounting for $50 \%$ of the world total production. Ginger is cultivated in most of the states in India. Kerala, Meghalaya, Arunachal Pradesh, Mizoram, Sikkim, Nagaland and Odisha together contribute 70 per cent of the country's total production. Ginger is grown in the Gudalur and Pandalur taluks of the Nilgiris district, Tamil Nadu in an area of 415.87 ha adjoining the state of Kerala (2017, Nilgiris Horticulture database). Gudalur block is a heavy rainfall receiving zone in the Nilgiris district and receives an average of $2000 \mathrm{~mm}$ per year. The average temperature ranges from $20^{\circ}$ to $35^{\circ} \mathrm{C}$ in Gudalur. The farmers of the Gudalur block of Nilgiris district cultivate the crop during the month of March to November.

Ginger is propagated commercially by vegetative method and chance of crop improvement programme is very limited. In such cases, alternate method is to collect, 
conserve and evaluate the different varieties grown under the diverse conditions suitable for specific agro-climatic conditions. The yield and quality of different ginger varieties varies according to the temperature and elevation. The soft rot disease caused by Pythium aphanidermatum in ginger is a major problem. The occurrence of per cent disease incidence in Gudalur regions is upto $40 \%$. It is basic need to develop high yielding varieties with better quality to increase the production and productivity of ginger in India. The varieties Maran, Thadimaran and Rio-deJanerio are mostly cultivated in Gudalur regions. The average yield obtained by the farmers from these varieties is 12.50 tonnes per hectare. The study was planned to collect different varieties of ginger genotypes and to evaluate the performance of the accessions for high yield and resistance to soft rot disease suitable for Gudalur regions of the Nilgiris district.

\section{Materials and Methods}

A field experiment was conducted for three seasons to evaluate the performance of collected genotypes at Hybrid Rice Evaluation Centre, Tamil Nadu Agricultural University Gudalur, The Nilgiris district during the year 2015 - 2018. A total of fourteen genotypes of ginger from Indian Institute of Spices Research, Calicut and local collections from Gudalur areas were collected and planting was taken up during the month of May, 2015 during the first season. Protray nursery techniques was followed for sprouting of rhizomes and after one month; sprouted, well grown plantlets were transplanted in main field. Field was prepared and planting of uniform sprouted rhizomes of 30 - 40 grams size was taken up with a spacing of $20 \times 20$ $\mathrm{cm}$ between the rows and in between the plants. The performance of the collected 14 genotypes was assessed for its important growth and yield characters for the three season crop. Data on the morphological and yield parameters were collected from mean of randomly selected five plants from each genotype in each replication. The vegetative and yield parameters viz., plant height $(\mathrm{cm})$, number of leaves per plant, number of tillers per plant, individual rhizome weight $(\mathrm{kg})$, yield per plot $(\mathrm{kg})$, length and girth of the rhizome $(\mathrm{cm})$ were recorded at critical stages of crop growth. The vegetative parameters observed during 150 days after planting was recorded and presented in the table for interpretation.

Screening studies on the resistance to soft rot disease were carried out in pot culture and observed in field conditions. The per cent disease incidence (PDI) was calculated by counting the number of plants affected per plot divided by total number of plants in each plot multiplied by 100 . First observation was taken up four months after sowing at tillering stage. After a fortnight, second observation was taken up at active tillering stage. Third observation was taken up at the beginning of rhizome bulking stage. Mean of three observations were recorded as annual PDI of each varieties (Senapati and Sugata Ghose, 2005). The varieties were grouped based on the percentage of resistance. The ginger genotypes namely ACC - 578, Mahima, Athira, Aswathi, IISR - 1 GB, GCP - 49, Rejetha, Varada, ACC-581, Karthika, Maran, Thadimaran, Rio-de-janerio, Gudalur local were collected. The treatment was laid out by randomized block design with two replications. The crop cultivation was done by following the standard package of practices recommended in crop production guide. The data collected were statistically analyzed by following the procedure of Panse and Sukhatme (1967).

\section{Results and Discussion}

The results of the experimental study taken up during the three years were discussed and interpreted based on the performance of the 
genotypes. The Table 1 shows significant variations among the genotypes for important growth and yield attributes for the crop grown during 2015-2016. Among the fourteen types collected and evaluated, the plant height in Acc - 578 recorded maximum $(43.20 \mathrm{~cm})$ followed by Rio-de-janerio $(41.70 \mathrm{~cm})$, Gudalur local $(41.40 \mathrm{~cm})$ and the least plant height was noticed in Karthika $(15.40 \mathrm{~cm})$. The plant height of different accessions ranged between $15.40 \mathrm{~cm}$ to $43.20 \mathrm{~cm}$. The genotype Gudalur local recorded maximum number of leaves per plant (229.80) followed by Rio-dejanerio which recorded 204.00. The number of tillers per plant was maximum in Gudalur local (19.80). The individual weight of rhizome in the variety Rio-de-janerio recorded maximum weight of $232.00 \mathrm{~g}$ and yield per plot $\left(4 \mathrm{~m}^{2}\right)$ of $10.10 \mathrm{~kg}$. Karthika recorded lowest individual rhizome yield of $16.00 \mathrm{~g}$ per plot. The varieties Athira (0.68 $\mathrm{kg})$, ACC-581 $(0.21 \mathrm{~kg})$, Karthika $(0.12 \mathrm{~kg})$ recorded lowest yield per plot during the first season.

The mean of second and third season data (2016 - 2017 \& 2017 - 2018) was combined in Table 2 and the results are interpreted. Significant variations were observed in terms of vegetative, yield and resistance to soft rot incidence grown under Gudalur condition. Acc - 578 recorded maximum plant height $(78.75 \mathrm{~cm})$ followed by Mahima $(72.15 \mathrm{~cm})$ and lowest plant height was recorded in Karthika $(24.40 \mathrm{~cm})$. More number of leaves per plant (113.70) was recorded in Acc-578. GCP-49 recorded maximum number of tillers per plant (17.40) followed by Acc-578 (15.0) during 150 days after planting for the vegetative parameters. Mahima recorded maximum girth of rhizome $(3.75 \mathrm{~cm})$ and lowest in ACC-581 $(1.60 \mathrm{~cm})$.

Table.1 Performance of genotypes for vegetative and yield characters during the first crop

(2015 - 2016)

\begin{tabular}{|l|l|c|c|c|c|c|}
\hline $\begin{array}{l}\text { S. } \\
\text { No. }\end{array}$ & $\begin{array}{l}\text { Genotypes/ } \\
\text { Collections }\end{array}$ & $\begin{array}{c}\text { Plant height } \\
\text { @ 150 DAP }\end{array}$ & $\begin{array}{c}\text { Number of leaves } \\
\text { per plant @ 150 } \\
\text { DAP }\end{array}$ & $\begin{array}{c}\text { Number of } \\
\text { tillers/plant } \\
\text { @ } 150 \text { DAP }\end{array}$ & $\begin{array}{c}\text { Individual } \\
\text { rhizome } \\
\text { weight (g) }\end{array}$ & $\begin{array}{c}\text { Yield per } \\
\text { plot (kg) } \\
\text { (4 x 1 m) }\end{array}$ \\
\hline $\mathbf{1 .}$ & ACC - 578 & 43.20 & 134.40 & 10.20 & 170.50 & 8.55 \\
\hline $\mathbf{2 .}$ & Mahima & 33.70 & 102.60 & 8.80 & 151.00 & 3.27 \\
\hline $\mathbf{3 .}$ & Athira & 30.20 & 91.80 & 7.80 & 48.50 & 0.68 \\
\hline $\mathbf{4 .}$ & Aswathi & 30.80 & 96.20 & 8.60 & 90.50 & 2.14 \\
\hline $\mathbf{5 .}$ & IISR - 1 GB & 30.00 & 91.60 & 7.20 & 99.50 & 3.00 \\
\hline $\mathbf{6 .}$ & GCP - 49 & 34.40 & 104.20 & 8.80 & 168.00 & 4.47 \\
\hline $\mathbf{7 .}$ & Rejetha & 30.40 & 84.40 & 7.40 & 95.00 & 1.23 \\
\hline $\mathbf{8 .}$ & Varada & 37.60 & 112.60 & 10.60 & 94.00 & 2.93 \\
\hline $\mathbf{9 .}$ & ACC-581 & 30.20 & 97.00 & 9.80 & 67.50 & 0.21 \\
\hline $\mathbf{1 0 .}$ & Karthika & 15.40 & 59.80 & 5.60 & 16.00 & 0.12 \\
\hline $\mathbf{1 1 .}$ & Maran & 31.70 & 101.00 & 7.80 & 196.00 & 3.57 \\
\hline $\mathbf{1 2 .}$ & Thadimaran & 33.00 & 152.00 & 11.80 & 179.50 & 4.71 \\
\hline $\mathbf{1 3 .}$ & Rio-de-janerio & 41.70 & 204.00 & 18.60 & 232.00 & 10.10 \\
\hline $\mathbf{1 4}$ & Gudalur local & 41.40 & 229.80 & 19.80 & 42.50 & 1.67 \\
\hline & Mean & 33.12 & 118.67 & 10.20 & 117.89 & 3.33 \\
\hline & SE(d) & 1.37 & 1.68 & 0.47 & 1.27 & 0.15 \\
\hline & CD $(\mathbf{0 . 0 5 )}$ & 2.96 & 3.64 & 1.01 & 2.75 & 0.33 \\
\hline & & & & & \\
\hline
\end{tabular}

* DAP - Days after planting 
Int.J.Curr.Microbiol.App.Sci (2018) 7(7): 2979-2985

Table.2 Mean performance of ginger genotypes for vegetative and yield characters during the second and third season crop (2016 - 2018)

\begin{tabular}{|c|c|c|c|c|c|c|c|c|}
\hline $\begin{array}{l}\text { S. } \\
\text { No. }\end{array}$ & $\begin{array}{l}\text { Genotypes/ } \\
\text { Collections }\end{array}$ & $\begin{array}{c}\text { Plant } \\
\text { height } \\
@ \\
150 \\
\text { DAP }\end{array}$ & $\begin{array}{c}\text { Number of } \\
\text { leaves per } \\
\text { plant @ } \\
150 \text { DAP }\end{array}$ & $\begin{array}{c}\text { Number } \\
\text { of tillers/ } \\
\text { plant@ } \\
150 \text { DAP }\end{array}$ & $\begin{array}{l}\text { Length } \\
\text { of } \\
\text { rhizome } \\
(\mathrm{cm})\end{array}$ & $\begin{array}{l}\text { Girth of } \\
\text { rhizome } \\
(\mathrm{cm})\end{array}$ & $\begin{array}{l}\text { Weight of } \\
\text { individual } \\
\text { rhizome } \\
\text { (g) }\end{array}$ & $\begin{array}{l}\text { Fresh } \\
\text { rhizome } \\
\text { yield per } \\
\text { plot }(g) \\
(6 x 1 \mathrm{~m})\end{array}$ \\
\hline 1. & ACC - 578 & 78.75 & 113.70 & 15.00 & 31.00 & 3.65 & 696.40 & 20.00 \\
\hline 2. & Mahima & 72.15 & 77.23 & 13.35 & 23.50 & 3.75 & 384.30 & 15.50 \\
\hline 3. & Athira & 39.15 & 83.56 & 7.80 & 23.00 & 1.95 & 154.40 & 1.97 \\
\hline 4. & Aswathi & 49.70 & 94.34 & 10.90 & 33.50 & 3.43 & 504.90 & 11.65 \\
\hline 5. & IISR - 1 GB & 61.45 & 96.85 & 8.95 & 25.00 & 2.75 & 291.15 & 14.00 \\
\hline 6. & GCP - 49 & 57.50 & 107.28 & 17.40 & 32.00 & 2.95 & 308.65 & 15.75 \\
\hline 7. & Rejetha & 46.45 & 80.10 & 8.10 & 23.50 & 2.85 & 252.40 & 7.75 \\
\hline 8. & Varada & 50.15 & 51.28 & 7.65 & 26.50 & 2.18 & 163.65 & 2.53 \\
\hline 9. & ACC-581 & 30.50 & 21.08 & 4.40 & 21.25 & 1.60 & 74.80 & 0.43 \\
\hline 10. & Karthika & 24.40 & 12.26 & 4.50 & 18.50 & 1.75 & 76.75 & 0.32 \\
\hline 11. & Maran & 45.80 & 48.24 & 9.40 & 29.00 & 2.50 & 265.25 & 9.75 \\
\hline 12. & Thadimaran & 54.45 & 81.71 & 10.30 & 31.75 & 3.18 & 417.75 & 10.05 \\
\hline 13. & Rio-de-janerio & 36.95 & 29.68 & 6.20 & 32.00 & 3.80 & 442.30 & 8.35 \\
\hline \multirow[t]{4}{*}{14.} & Gudalur local & 41.15 & 64.09 & 11.75 & 25.00 & 3.35 & 269.30 & 2.80 \\
\hline & Mean & 49.18 & 68.67 & 9.70 & 26.72 & 2.83 & 307.29 & 8.64 \\
\hline & $\mathrm{SE}(\mathrm{d})$ & 1.58 & 3.46 & 0.46 & 0.62 & 0.88 & 17.72 & 0.76 \\
\hline & CD (0.05) & 1.98 & 6.78 & 0.39 & 0.54 & 0.70 & 15.01 & 0.66 \\
\hline
\end{tabular}

* DAP - Days after planting

Table.3 Screening of ginger varieties against rhizome rot disease under invitro culture

\begin{tabular}{|l|l|c|}
\hline S. No & \multicolumn{1}{|c|}{ Variety } & PDI \\
\hline $\mathbf{1}$ & Varada & 30.21 \\
\hline $\mathbf{2}$ & GCP-49 & 28.64 \\
\hline $\mathbf{3}$ & Thadimaran & 11.26 \\
\hline $\mathbf{4}$ & Rio-de-Janerio & 3.92 \\
\hline $\mathbf{5}$ & Rejetha & 4.12 \\
\hline $\mathbf{6}$ & Acc -578 & 7.61 \\
\hline $\mathbf{7}$ & Acc - 581 & 18.72 \\
\hline $\mathbf{8}$ & Athira & 19.56 \\
\hline $\mathbf{9}$ & Aswathi & 35.64 \\
\hline $\mathbf{1 0}$ & IISR-1 GB & 4.21 \\
\hline $\mathbf{1 1}$ & Gudalur local & 9.42 \\
\hline $\mathbf{1 2}$ & Mahima & 20.16 \\
\hline $\mathbf{1 3}$ & Karthika & 19.84 \\
\hline $\mathbf{1 4}$ & Maran & 3.12 \\
\hline
\end{tabular}


Grouping of ginger varieties screened against rhizome rot

\begin{tabular}{|c|l|l|}
\hline \multicolumn{1}{|c|}{ PDI } & \multicolumn{1}{|c|}{ Category } & \multicolumn{1}{|c|}{ Name of variety } \\
\hline $\mathbf{1 . 0}$ to $\mathbf{5 . 0}$ & Resistant & \multicolumn{1}{c|}{-} \\
\hline $\mathbf{6 . 0}$ to $\mathbf{1 5 . 0}$ & Toderately resistant & $\begin{array}{l}\text { Rejetha, Maran, Rio-de Janerio, } \\
\text { IISR-1GB }\end{array}$ \\
\hline $\mathbf{1 6 . 0}$ to $\mathbf{2 5 . 0}$ & Moderately tolerant & $\begin{array}{l}\text { Acc 578, Gudalur local, } \\
\text { Thadimaran }\end{array}$ \\
\hline $\mathbf{2 6 . 0}$ to 40.0 & $\begin{array}{l}\text { Acc- 581, Athira, Mahima, } \\
\text { Karthika }\end{array}$ \\
\hline above 40 & Susceptible & Aswathi, Varada, GCP-49 \\
\hline
\end{tabular}

Table.4 Screening of ginger varieties against rhizome rot disease under field condition

\begin{tabular}{|l|l|r|}
\hline S. No & \multicolumn{1}{|c|}{ Variety } & PDI \\
\hline $\mathbf{1}$ & ACC - 578 & 10.00 \\
\hline $\mathbf{2}$ & Mahima & 21.00 \\
\hline $\mathbf{3}$ & Athira & 19.50 \\
\hline $\mathbf{4}$ & Aswathi & 29.00 \\
\hline $\mathbf{5}$ & IISR - 1 GB & 5.00 \\
\hline $\mathbf{6}$ & GCP - 49 & 38.00 \\
\hline $\mathbf{7}$ & Rejetha & 12.00 \\
\hline $\mathbf{8}$ & Varada & 36.50 \\
\hline $\mathbf{9}$ & ACC-581 & 18.00 \\
\hline $\mathbf{1 0}$ & Karthika & 42.50 \\
\hline $\mathbf{1 1}$ & Maran & 3.50 \\
\hline $\mathbf{1 2}$ & Thadimaran & 4.50 \\
\hline $\mathbf{1 3}$ & Rio-de-janerio & 25.00 \\
\hline $\mathbf{1 4}$ & Gudalur local & 11.00 \\
\hline
\end{tabular}

Grouping of ginger varieties screened against rhizome rot

\begin{tabular}{|c|l|l|}
\hline PDI & \multicolumn{1}{|c|}{ Category } & \multicolumn{1}{c|}{ Name of variety } \\
\hline $\mathbf{0 . 0}$ & Resistant & \multicolumn{1}{c|}{-} \\
\hline $\mathbf{1 . 0}$ to $\mathbf{5 . 0}$ & Moderately resistant & IISR - 1 GB, Maran, Thadimaran \\
\hline $\mathbf{6 . 0}$ to 15.0 & Tolerant & ACC - 578, Rejetha, Gudalur local \\
\hline $\mathbf{1 6 . 0}$ to 25.0 & Moderately tolerant & $\begin{array}{l}\text { Mahima, Athira, ACC-581, } \\
\text { Rio-de-janerio }\end{array}$ \\
\hline $\mathbf{2 6 . 0}$ to 40.0 & Susceptible & Varada, GCP - 49 \\
\hline above 40 & Highly susceptible & Karthika \\
\hline
\end{tabular}


Aswathi recorded maximum length of rhizome $(33.50 \mathrm{~cm})$ followed by GCP-49 $(32.0 \mathrm{~cm})$ and lowest in Karthika $(18.5 \mathrm{~cm})$. Rio-de-janerio Acc-578 recorded $20.0 \mathrm{~kg}$ of fresh rhizome yield per plot $\left(6 \mathrm{~m}^{2}\right)$, weight of individual rhizome $(696.40 \mathrm{~g})$. The lowest fresh rhizome yield per plot was recorded in Karthika (0.32 kg per plot). The highest fresh rhizome yield produced by some of these varieties can be mainly attributed to vegetative growth characters like plant height, number of leaves per plant, fresh weight of rhizomes, length of rhizome and girth of rhizome. It can be attributed that the yield of a variety is dependent on vigour of the plant and other rhizome characters (Sanwal et al., 2012; Chongtham et al., 2013; Raviraja Shetty et al., 2015).

\section{Reaction to per cent disease incidence against soft rot resistance}

The per cent disease incidence of the genotypes was assessed based on the performance of each genotype with respect to its resistance to soft rot under in vitro and in vivo conditions. The genotypes IISR - $1 \mathrm{~GB}$, Maran, Thadimaran were found to be moderately resistant which ranges between 1.0 to 5.0. The genotypes ACC -578, Rejetha, Gudalur local were found to be tolerant under the category of 6.0 to 15.0. The genotypes Mahima, Athira, ACC-581, Rio-dejanerio were found to be moderately tolerant under the category of 16.0 to 25.0. Varada, GCP - 49 expressed susceptible with a score of 26.0 to 40.0. Aswathi recorded maximum percent disease incidence of 35.64 and Maran recorded minimum percent disease incidence of 3.12 under invitro culture experiment (Table 3 ).

The variety Maran recorded minimum per cent disease incidence (PDI) of 3.50 and Karthika recorded maximum per cent disease incidence under field experiment. The accessions IISR-1GB, Maran, Thadimaran expressed moderate resistant (1.0 to 5.0), Acc-578, Rejetha and Gudalur local (6.0 to 15.0) recorded tolerance to soft rot incidence. The varieties Mahima, Athira, Acc-581, Riode-janerio recorded moderate resistance (16.0 to 25.0) and Varada, GCP-49 were susceptible (26.0 to 40.0) to soft rot. The variety Karthika was highly susceptible to soft rot disease of ginger under Gudalur conditions (Table 4).

In conclusion, the overall performance of Acc-578 recorded better for vegetative and yield parameters followed by Mahima. IISR-1 GB, Maran and Thadimaran recorded moderate resistance with low per cent disease incidence under field conditions in the Nilgiris.

\section{Acknowledgement}

The authors gratefully thank and acknowledge Dr. Prasath, Principal Scientist, ICAR - Indian Institute of Spices Research, Calicut for providing genotypes and varieties to take up the evaluation study and Professor \& Head, Hybrid Rice Evaluation Centre, Gudalur for providing support for carrying out the research work.

\section{References}

A.K. Senapati and Sugata Ghose, 2005. Screening of ginger varieties against rhizome rot disease complex in eastern ghat high land zone of Orissa Indian Phytopath. 58 (4): 437-439.

Chongtham,T., Chatterjee, R., Hnamte, V., Chattopadhyay, P.K. and Khan, S.A. 2013. Ginger (Zingiber officinale Rosc.) germplasm evaluation for yield and quality in southern West Bengal, J. Spices and Aromatic Crops, 22(1): 88-90.

Panse, V. G. and Sukhatme, P. V. 1967. 
Statistical Methods for Agriculture Workers. Indian Council of Agricultural Research. New Delhi. p.155.

Raviraja Shetty, G., Kallappa Narode and Venkatesha. J. 2015. Performance of ginger (Zingiber officinale Rosc.) varieties under hill zone of Karnataka.
Environ. and Ecol., 33(3): 1196-2000. Sanwal, S.K., Singh, S.K., Yadav, R.K., Singh. P.K and Misra. A.K. 2012. Yield and quality assessment of ginger (Zingiber officinale Rosc.) genotypes. Indian J. plant Genet. Resour., 25(3): $281-286$.

\section{How to cite this article:}

Karthikeyan, S., M. Anand, S. Malathi and Manonmani, S. 2018. Evaluation of Ginger (Zingiber officinale) Genotypes for High Yield and Resistance to Soft Rot Suitable for Gudalur Regions in Nilgiris District. Int.J.Curr.Microbiol.App.Sci. 7(07): 2979-2985. doi: https://doi.org/10.20546/ijcmas.2018.707.348 